\title{
The applicability of C-I4 measurements in the soil gas for the assessment of leakage out of underground carbon dioxide reservoirs
}

\author{
Stanisław Chałupnik, \\ Małgorzata Wysocka
}

\begin{abstract}
Poland, due to the ratification of the Kioto Protocol, is obliged to diminish the emission of greenhouse gases. One of the possible solutions of this problem is $\mathrm{CO}_{2}$ sequestration (CCS - carbon capture and storage). Such an option is a priority in the European Union. On the other hand, $\mathrm{CO}_{2}$ sequestration may be potentially risky in the case of gas leakage from underground reservoirs. The most dangerous event may be a sudden release of the gas onto the surface. Therefore, it is very important to know if there is any escape of $\mathrm{CO}_{2}$ from underground gas reservoirs, created as a result of sequestration. Such information is crucial to ensure safety of the population in areas located above geological reservoirs. It is possible to assess the origin of carbon dioxide, if the measurement of radiocarbon ${ }^{14} \mathrm{C}$ concentration in this gas is done. If $\mathrm{CO}_{2}$ contains no ${ }^{14} \mathrm{C}$, it means, that the origin of the gas is either geological or the gas has been produced as a result of combustion of fossil fuels, like coal. A lot of efforts are focused on the development of monitoring methods to ensure safety of $\mathrm{CO}_{2}$ sequestration in geological formations. A radiometric method has been tested for such a purpose. The main goal of the investigations was to check the application possibility of such a method. The technique is based on the liquid scintillation counting of samples. The gas sample is at first bubbled through the carbon dioxide adsorbent, afterwards the adsorbent is mixed with a dedicated cocktail and measured in a low-background liquid scintillation spectrometer Quantulus. The described method enables measurements of ${ }^{14} \mathrm{C}$ in mine and soil gas samples.
\end{abstract}

Key words: greenhouse gases $\bullet$ carbon dioxide sequestration $\bullet$ radiocarbon $\bullet$ liquid scintillation spectrometry

S. Chałupnik ${ }^{\bowtie}$, M. Wysocka

Silesian Centre for Environmental Radioactivity,

Central Mining Institute,

1 Gwarków Sq., 40-166 Katowice, Poland,

Tel.: +48 32259 2815, Fax: +48 322592295 ,

E-mail: schalupnik@gig.eu

Received: 23 October 2012

Accepted: 26 November 2013

\section{Introduction}

Radiocarbon ${ }^{14} \mathrm{C}$ is a radioactive nuclide of carbon, with a half-life equal to $5730 \pm 40$ years. This nuclide is produced in the atmosphere as a result of the interaction of nitrogen with cosmic radiation and therefore is homogeneously spread in the air. ${ }^{14} \mathrm{C}$ in the form of carbon dioxide is involved in photosynthesis and enters the organic carbon cycle in the environment. Its abundance is $0.00000000012 \%$ only [1]. In the atmosphere and surface waters it corresponds to the concentration of about $1 \mathrm{ppt}$. In terms of activity concentration it is equal roughly to $0.225 \mathrm{~Bq}{ }^{14} \mathrm{C}$ in each gram of carbon.

One of the possible hazards in the case of underground carbon dioxide sequestration, as well as during underground gasification of coal, is the escape of carbon dioxide and release of this gas onto the surface [2]. Therefore, monitoring of carbon dioxide content in the strata and in soil in the vicinity of gas reservoirs is very important. It is necessary to point out a very important issue, related to radiocarbon presence. Fossil fuels contain no radiocarbon ${ }^{14} \mathrm{C}$, due to its age. Therefore, after combustion of such fuels the resulting carbon dioxide contains no radiocarbon as well. It means that $\mathrm{CO}_{2}$ introduced into the strata during sequestration or produced during coal gasification will have no traces of ${ }^{14} \mathrm{C}$. On the contrary, the soil gas contains carbon dioxide, produced during 
biological processes like respiration, fermentation, etc. and, therefore, ${ }^{14} \mathrm{C}$ is present there. Measuring radiocarbon content in the soil gas, it is possible to estimate the origin of the gas - geological or biological [3].

Sequestration of $\mathrm{CO}_{2}$ is the process consisting of three main parts - separation of carbon dioxide from combustion gases, transport of $\mathrm{CO}_{2}$ to the storage site and final disposal or neutralization (CCS - carbon capture and storage). The main goal of the sequestration is to decrease the carbon dioxide emission, coming from combustion of fossil fuels, like coal in Poland. Such a technology can be applied first of all at big power stations $[4,5]$.

In general, the methods of carbon dioxide collection can be divided into the following groups:

- secondary methods - carbon dioxide is separated from "typical" combustion gases,

- primary methods - the solid fuel is transformed into gas before combustion and afterwards $\mathrm{CO}_{2}$ is collected,

- oxycombustion methods - combustion of the fuel is done in oxygen, therefore the combustion gas contains mostly carbon dioxide and steam.

Proposed methods of $\mathrm{CO}_{2}$ sequestrations are the following:

- in deep oceans,

- in geological structures,

- in the mineral form (for instance, the reaction $\mathrm{CaO}$ $+\mathrm{CO}_{2}$ gives solid $\mathrm{CaCO}_{3}$ ).

In Poland the following possibilities are taken into account for the sequestration of $\mathrm{CO}_{2}$ [6]:

- use of empty and exploited reservoirs of hydrocarbons (oil and gas),

- deep coal seans,

- deep aquifers of brines (high salinity waters).

A pilot study of sequestration in a deep coal seams to be done by the Central Mining Institute and partners with the RECOPOL [7]. In the vicinity of Silesia Mine in southern Poland 760 tones of carbon dioxide has been stored. In the previous period a mass spectrometric method based of stable carbon isotopes (delta C-13) was applied to test the leakage of the reservoir [7] without positive results. We proposed to use a method based on C-14 measurements. Our goal was to check the risk of leakage from this reservoir.

\section{Measurement and sampling methods}

Radiocarbon ${ }^{14} \mathrm{C}$ is a beta-emitting radionuclide, with a maximum beta energy of $156 \mathrm{keV}$. There is no emission of gamma rays during decay, therefore no possibility of gamma spectrometry exists. It is necessary to apply other measuring techniques, like liquid scintillation spectrometry (LSC), proportional counters or accelerator mass spectrometry (AMS) [8]. The most widely spread method is LSC, although lately more and more important is AMS. In our case it was convenient to use the LSC method for measurements of radiocarbon in mine gases. The most difficult task was to develop the sampling technique of the gas and sample preparation suitable for further LSC measurements.

The reagent, most commonly used for the adsorption of $\mathrm{CO}_{2}$ from the air is an organic chemical, 3-metoxypropylamine. It is known under commercial brands as Carbo-Sorb E (PerkinElmer) or CarbonTrap (Meridian). This substance is able to adsorb $48 \mathrm{mmols}$ of carbon dioxide per $10 \mathrm{ml}$ of its volume [9]. Later, the adsorbent can be mixed with a suitable scintillation cocktail to obtain a final sample, ready for measurement. For this purpose the following cocktail can be used $[10,11]$ Permafluor E+ (PerkinElmer) or CarbonCount (Meridian).

A significant drawback of this technique of sample preparation is the lack of possibility of checking the saturation of the 3-metoxypropylamine with carbon dioxide. When $\mathrm{CO}_{2}$ is not fully loaded to the adsorbent, the measurement would show on increase of the content of non-biological carbon dioxide in the sample (there is a negative effect of the carbon relative content in the final sample). Therefore, very important is the surplus of the $\mathrm{CO}_{2}$ transferred into metoxypropylamine. If we take into account such assumption it leads to the conclusion that the sample volume should be at least 51 of gas (if the content of carbon dioxide is of about $20 \%$ ). On the other hand, even for a much lower volume of carbon dioxide it would be possible to assess the presence of C-14 in the sample.

Another difficulty is the direct use of dangerous chemical in the underground galleries. Due to this fact, a sampling technique is based on the application of polyethylene air sampling bags with a volume of 51 (Fig. 1) produced by the Department of Aerology in the Central Mining Institute. The mine gas is sampled in the mine to the air-tight bags with the application of a standard pump, being used for air sampling in mines. The desiccant has been used to remove humidity from the air. Afterwards, the air samples were transported to the laboratory. Then, metoxypropylamine was used for the absorption of $\mathrm{CO}_{2}$ from these samples. The gas from the plastic bags has been pumped through the bubbler containing $15 \mathrm{ml}$ of 3-metoxypropylamine. At the end of this procedure, $10 \mathrm{ml}$ of the adsorber has been transferred to a teflon scintillation vial and $10 \mathrm{ml}$ of Permafluor E+ scintillation cocktail has been added.

In our measurements the low-background liquid scintillation spectrometer Quantulus (PerkinElmer) has been used. Due to the heavy lead passive shielding built of $630 \mathrm{~kg}$ of lead with a very low content of radioactive impurities as well as due to the application of active shielding (anticoincidence mode) application of the spectrometer ensures a very low background in radiocarbon measurements. The beta emission of ${ }^{14} \mathrm{C}$ has a rather low maximum energy $-156 \mathrm{keV}$ only, therefore this feature is very important.

Another important issue is the application of low-background scintillation vials, therefore no glass vials have been used for this purpose. Typically, polyethylene or teflon vials are applied for radiocarbon counting. Slightly lover background can be achieved with the use of teflon vials, therefore we decided to use such vials for the measurements.

Setting counting windows of the liquid scintillation spectrometer Quantulus has been made with the application of standards and blank samples, containing no radiocarbon, to measure the background and calculate the detection limit. Standard samples with a known ${ }^{14} \mathrm{C}$ activity have been used for the adjusting counting windows, and calculation of a counting efficiency for 


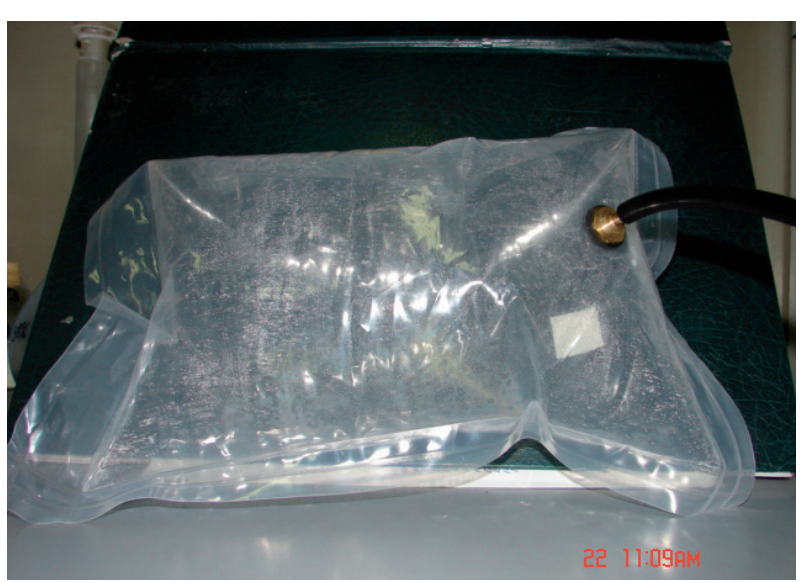

Fig. 1. Sampling bag with a volume of 51 .

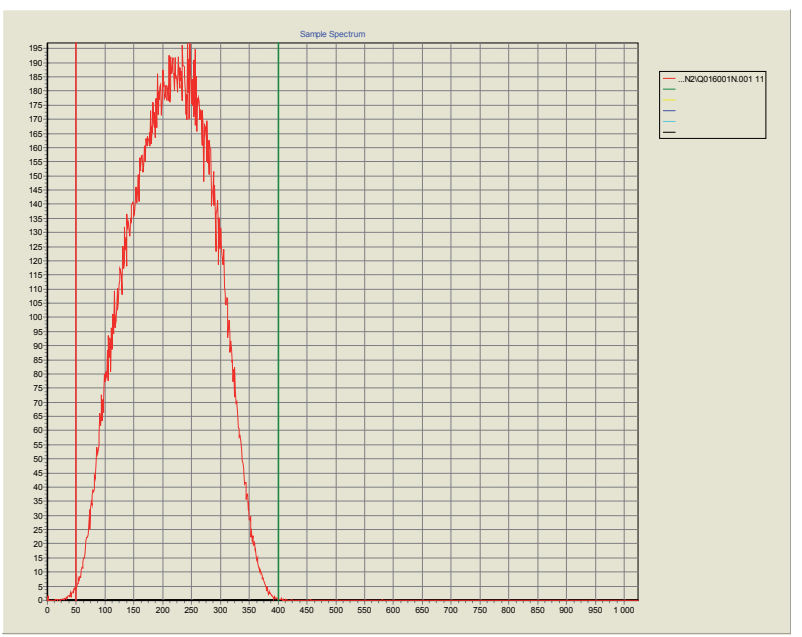

Fig. 2. The spectrum of ${ }^{14} \mathrm{C}$ standard, used for setting of the counting windows.

${ }^{14} \mathrm{C}$. The blank samples and standard samples have been prepared from the mixture of Carbo-Sorb and Permafluor E+ the volume ratio being 10 to $10 \mathrm{ml}$. Additionally, to standard samples special ${ }^{14} \mathrm{C}$ standard sources have been added (Fig. 2).

On the basis of the measurements of standards and blanks, two counting windows have been chosen, the first one in the range of channels between 50-400 and the second one narrower, between the channels 150-400. The main reason of such setting is chemoluminescence, the light emission due to the chemical reactions in the samples in low energy region (Fig. 3). When the measurement of the blank sample is done quickly after preparation, then chemoluminesce is clearly visible (red curve in Fig. 3). When the counting is done $48 \mathrm{~h}$ later, no such effect is observed (see green curve in Fig. 3). Therefore, for samples, while measured immediately after preparation, the narrower window must be applied to avoid overestimation of the radiocarbon concentration. In mine gas samples a radioactive noble gas radon $\left({ }^{222} \mathrm{Rn}\right)$ is present. To be sure that the influence of its disturbing effects can be neglected, the following counting procedure has been proposed and applied. The first measurement is done 24-48 h after sample preparation to check the quality of the sample and for rough estimation of the results. The second measurement is done a month later and the results are used for the calculation of radiocarbon concentration in the samples. During this period, radon decays

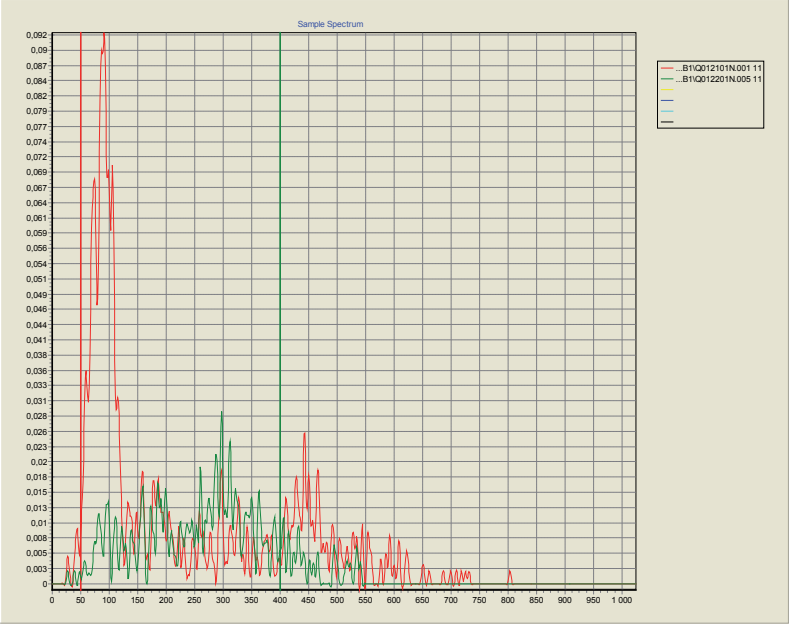

Fig. 3. Spectra of the blank sample. Red curve - counting done several hours after sample preparation; green curve measurement done $48 \mathrm{~h}$ after sample preparation.

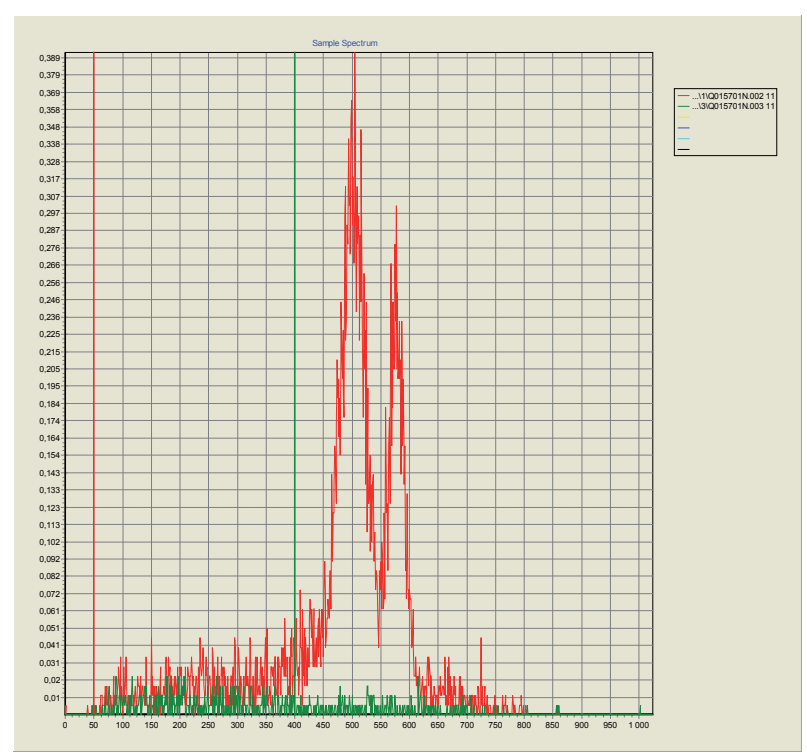

Fig. 4. Presence of ${ }^{222} \mathrm{Rn}$ in gas samples. Red curve - measurement done $24 \mathrm{~h}$ after sampling; green curve - measurement done one month after sampling.

almost completely and chemoluminescence is gone, too (Fig. 4). Although for cases when preliminary results were needed badly, the narrower counting window was chosen to minimize the undesirable effects.

Measurements of the blank samples and standards have been done at first, to adjust the chosen windows settings and to assess the background values for the chosen vials (Fig. 2). We found that in the narrow counting window (channels 150-400) the background counting rate for teflon vials was at a level IB $=1.30-1.40 \mathrm{cpm}$ (counts per minute). On this basis, we were able to estimate the suitable counting time as well as the decision threshold and detection limit for ${ }^{14} \mathrm{C}$. It has been estimated that the counting time should be at least $5 \mathrm{~h}$.

Calculations of the decision threshold and detection limit were performed for the counting time equal to $5 \mathrm{~h}$ (18000 s) for gas samples, blanks and standards. Counting efficiency $(\varepsilon)$ has been established on the basis of measurements of standard samples. For measurements standards with activity $\mathrm{A}=45600 \mathrm{dpm}$ (disintegrations per minute) were taken and the average counting rate 
was equal to IS $=25800 \mathrm{cpm}$, so the calculated value of counting efficiency is

$$
\varepsilon=(\mathrm{IS}-\mathrm{IB}) / \mathrm{A}=25800 / 45600=0.56 .
$$

The percentage of modern carbon content has been calculated according to the following formula

$$
\mathrm{mCO}_{2}(\%)=100 / 60 *(\mathrm{I}-\mathrm{IB}) * \mathrm{~A} /(\mathrm{IS}-\mathrm{IB})
$$

where: $\mathrm{mCO}_{2}$ - percentage of modern carbon in the sample, I - counting rate (intensity) for the sample, IB - counting rate for the blank sample, IS - counting rate for the C-14 standard, A - activity of the C-14 standard, $100 / 60$ - factor for the conversion into percent (100) and from minutes to seconds (60).

It must be taken into account that calculations have been made on the assumption that the sample is saturated, and this means that the sample should contain roughly $2 \mathrm{~g}$ of carbon dioxide. The respective mass of carbon is $12 / 44$ part of the total mass of $\mathrm{CO}_{2}$ - therefore, it would be of about $0.55 \mathrm{~g}$ for the saturated sample. Taking into consideration the literature data $[12,13]$ that the ${ }^{14} \mathrm{C}$ content in carbon is $0.225(\mathrm{~Bq} / \mathrm{g}$ of carbon) it can be estimated that the ${ }^{14} \mathrm{C}$ activity in the sample made from the biological $\mathrm{CO}_{2}$ is $0.13 \mathrm{~Bq}$. The detection limit of the method is $0.0041 \mathrm{~Bq}$, therefore, it is possible to detect $5 \%$ of carbon dioxide from biological cycle (so-called modern carbon) in the presence of $95 \%$ non-biological $\mathrm{CO}_{2}$.

An additional problem appeared due to the presence of radon ( $\mathrm{Rn}$-222) in gas samples. It caused a significant delay of the final measurements of the samples after preparation. Radon has been adsorbed by 3-metoxypropylamine and despite the fact that only a small portion of radon has been adsorbed, nonetheless it has been visible in each spectrum of the gas samples together with radon decay products (Fig. 4). This caused an increase of counting rate in the ${ }^{14} \mathrm{C}$ window, difficult to compensate without special precautions. The half-life time of ${ }^{222} \mathrm{Rn}$ is roughly 3.82 days, therefore, it was necessary to allow radon to decay. According to the procedure for each batch the samples were left in a cooler for at least one month and measured afterwards. Due to such approach, there was no more radon in the sample at the time of final counting and the results of measurement in the low energy ${ }^{14} \mathrm{C}$ window were significantly lower then for the immediate measurements.

\section{Results of preliminary measurements}

Measurements and assessment of the contribution of the biological $\mathrm{CO}_{2}$ and radiocarbon in coal-mine gas samples have been made in the Silesia Colliery. As mentioned earlier, the assessment has been done on the assumption that the sample is fully saturated with $\mathrm{CO}_{2}$. In such a case the counting effect of radiocarbon (with an activity of $0.13 \mathrm{~Bq}$ ) would give the net counting rate $7.7 \mathrm{cpm}$, if the counting efficiency were $100 \%$. We found that the real counting efficiency for ${ }^{14} \mathrm{C}$ standards was $56 \%$ only (0.56). On this basis, the activity of ${ }^{14} \mathrm{C}$ has been calculated for each sample and the assessment of the biological carbon dioxide has been made. Results are shown in Table 1.

To compare the results for the mine gas with the measurements done for the soil gas, the results of monitoring of abandoned waste disposal site are shown in Table 2. The waste disposal has been used for dumping contemporary municipal waste material, containing "modern" carbon together with radiocarbon. Additionally, measurements of methane, carbon dioxide and oxygen content have been done in the degassing boreholes, left at the disposal site to prevent methane explosion or inflammation. Our results are proving the fact that the gas is mostly containing "modern" carbon, while some admixtures of carbon dioxide, resulting from oxidation of Carboniferous waste rocks, can be seen. The reason is that the thick layer of waste rocks from the mining industry, containing some amounts of hard coal, have been used to cover the area.

\section{Conclusions}

Our main goal was to check, if the radiocarbon measurements can be used for monitoring of the leakage

Table 1. Results of ${ }^{14} \mathrm{C}$ measurements in the mine gas from a Silesia mine

\begin{tabular}{rccc}
\hline Sampling date & Sampling point & $\begin{array}{c}\text { Counting rate }{ }^{14} \mathrm{C}, \\
\text { I (cpm) }\end{array}$ & $\begin{array}{c}\text { Estimated contribution } \\
\text { of "modern" } \mathrm{CO}_{2}(\%)\end{array}$ \\
\hline \multirow{2}{*}{ 5 May 2011 } & TP-1 & $1.40 \pm 0.07$ & $<5$ \\
& TP-2 & $1.51 \pm 0.08$ & $<5$ \\
& TI-417 & $1.48 \pm 0.08$ & $<5$ \\
5 May 2011 & TI-480 & $1.38 \pm 0.07$ & $<5$ \\
\hline
\end{tabular}

\begin{tabular}{|c|c|c|c|c|c|c|}
\hline $\begin{array}{l}\text { Sampling } \\
\text { date }\end{array}$ & $\begin{array}{l}\text { Sampling } \\
\text { point }\end{array}$ & $\begin{array}{c}\mathrm{CO}_{2} \text { content } \\
(\%)\end{array}$ & $\begin{array}{c}\mathrm{CH}_{4} \text { content } \\
(\%)\end{array}$ & $\begin{array}{c}\mathrm{O}_{2} \text { content } \\
(\%)\end{array}$ & $\begin{array}{l}\text { Counting rate } \\
{ }^{14} \mathrm{C}, \mathrm{I}(\mathrm{cpm})\end{array}$ & $\begin{array}{c}\text { Estimated } \\
\text { contribution } \\
\text { of "modern" } \mathrm{CO}_{2} \\
(\%)\end{array}$ \\
\hline \multirow{3}{*}{14 July 2010} & Degassing point I & $13.1 \pm 0.5$ & $11.1 \pm 0.5$ & 0.0 & $5.23 \pm 0.19$ & $93 \pm 4$ \\
\hline & Degassing point III & $19.9 \pm 0.6$ & $21.0 \pm 0.7$ & 0.0 & $4.84 \pm 0.17$ & $84 \pm 3$ \\
\hline & Degassing point IV & $26.2 \pm 0.7$ & $11.2 \pm 0.5$ & 0.0 & $4.66 \pm 0.17$ & $80 \pm 3$ \\
\hline
\end{tabular}

Table 2. Results of measurements of ${ }^{14} \mathrm{C}$ in the soil gas at the abandoned waste disposal site 
from underground carbon dioxide reservoirs. We were encouraged to make investigations due to the results of measurements, done within the frame of another project (Table 2). We found high concentrations of modern carbon in the soil gas in the area of abandoned waste dump. But we found a low ${ }^{14} \mathrm{C}$ level in the zone of the dump, where remnants of coal in Carboniferous rocks, used as a cover for municipal waste, started to burn in the presence of oxygen. This means that an additional flux of carbon dioxide originated from fossil fuel (coal) is leading to a significant decrease of ${ }^{14} \mathrm{C}$ level in the soil gas. Therefore, we assumed that a similar effect might be caused by possible leakage from the underground reservoir.

We received the samples of the carbon dioxide, used in sequestration experiments, showing no traces of ${ }^{14} \mathrm{C}$ in this gas. Due to this reason, we cannot exclude the possibility, that the origin of the carbon dioxide in the investigated samples is from the reservoir. On the other hand, our results can be treated mostly as a supporting data for the results of investigations of ${ }^{13} \mathrm{C}$, because the geological carbon dioxide should contain no ${ }^{14} \mathrm{C}$, too. Therefore, our results are not decisive ones. Unfortunately, also analyses of stable isotopes of carbon in the gas samples gave no results to confirm or exclude particular theories of gas origin [7].

Results of our preliminary investigations showed that mine gas samples contain no ${ }^{14} \mathrm{C}$ - therefore, the origin of the gas can be stated as either from geological structures or from the underground coal combustion. It is necessary to point out that carbon dioxide in the measured samples showed no presence of "modern" carbon of biological origin, as the ${ }^{14} \mathrm{C}$ concentrations were below the detection limit of the method, it means $5 \%$.

Another problem is related to the radon concentration in gas samples, leading to the significant delay in receiving results (usually at least one month). This makes the LSC method not very useful for fast monitoring. Therefore the final conclusion can be drawn that LSC is not a suitable technique for monitoring of leakage of underground carbon dioxide reservoirs.

\section{References}

1. Environmental radionuclides: tracers and timers of terrestrial processes. (2010). K. Froelich (Ed.), Radioactivity in the environment (Vol. 16), Series editor M. S. Baxter. Vienna: Elsevier.

2. Stańczyk, K., Howaniec, N., Smolinski, N., Świądrowski, J., Kapusta, K., Wiatowski, M., Grabowski, J., \& Rogut, J. (2011). Gasification of lignite and hard coal with air and oxygen-enriched air in a pilot scale ex-situ reactor for underground gasification. Fuel, 90(5), 1953-1962.

3. Michczyńska, D. J., Michczyński, A., \& Pazdur, A. (2007). Frequency distribution of radiocarbon dates as a tool for reconstructing environmental changes. Radiocarbon, 49(2), 799-806.

4. Hendriks, C., Graus, W., \& Van Bergen, F. (Eds.). (2004). Global carbon dioxide storage potential and costs. Utrecht: Ecofys and TNO.

5. Intergovernmental Panel on Climate Change. (2005). IPCC Special Report on Carbon Dioxide Capture and Storage. Prepared by Working Group III of the Intergovernmental Panel on Climate Change. B. Metz, O. Davidson, H. C. de Coninck, M. Loos, \& L. A. Meyer (Eds.). Cambridge: Cambridge University Press. Retrieved from https://www. ipcc.ch/pdf/special-reports/srccs/srccs_wholereport.pdf.

6. Tarkowski, R. (2005). Geological sequestration of $\mathrm{CO}_{2}$. Kraków: Wydawnictwo Instytutu Gospodarki Surowcami Mineralnymi i Energią PAN. (in Polish).

7. Krzystolik, P., Skiba, J., \& Jura, B. (2005). Monitoring of the parameters during sequestration of $\mathrm{CO}_{2}$ to the coal seams in the RECOPOL project (Upper Silesian Coal Basin, Poland). In Procedings of the 20th World Mining Congress (ICAMC session), 23 October -8 November 2005 (pp. 955-962). Tehran, Iran.

8. Culp, R., \& Noakes, J. (2009). Evaluation of bio-based content ASTM Method 6866-06A: Improvements revealed by liquid scintillation counting, accelerator mass spectrometry and stable isotopes for products containing inorganic carbon. In J. Eikenberg, M. Jäaggi, H. Beer, \& H. Baehrle (Eds.), LSC 2008 International Conference on Advances in Liquid Scintillation Spectrometry (pp. 269-278). Tucson, Arizona: Radiocarbon.

9. Edler, R. (2009). The use of LSC technology for the determination of biogenic materials. In J. Eikenberg, M. Jäggi, H. Beer, \& H. Baehrle (Eds.), LSC 2008 International Conference on Advances in Liquid Scintillation Spectrometry (pp. 261-267). Tucson, Arizona: Radiocarbon.

10. Molnar, M., Nagy, S., Svingor, E. \& Svetlik, I. (2005). Refining the $\mathrm{CO}_{2}$ absorption method for low-level ${ }^{14} \mathrm{C}$ liquid scintillation counting in the Atomki. In S. Chałupnik, F. Schoenhofer, \& J. Noakes (Eds). LSC 2005 International Conference on Advances in Liquid Scintillation Spectrometry (pp. 407-415). Tucson, Arizona: Radiocarbon.

11. Vartti, V. P. (2009). Optimizing the counting conditions for Carbon-14 for sample oxidizer-liquid scintillation counting method. In J. Eikenberg, M. Jäggi, H. Beer, \& H. Baehrle (Eds.). LSC 2008 International Conference on Advances in Liquid Scintillation Spectrometry (pp. 293-298). Tucson, Arizona: Radiocarbon.

12. Libby, W. F. (1952). Radiocarbon dating. Chicago: University of Chicago Press.

13. Walanus, A., \& Goslar, T. (2009). Radiocarbon dating. Kraków: Wydawnictwo Akademii Górniczo-Hutniczej. (in Polish). 